\title{
Effects Influencing Pedestrian-Vehicle Crash Frequency by Severity Level: A Case Study of Seoul Metropolitan City, South Korea
}

\author{
Seung-Hoon Park ${ }^{1, *(D)}$ and Min-Kyung Bae ${ }^{2}$ \\ 1 Department of Urban Planning, Keimyung University, Daegu 42601, Korea \\ 2 Land \& Housing Institute, Daejeon 34047, Korea; mk0224@lh.or.kr \\ * Correspondence: parksh1541@kmu.ac.kr; Tel.: +82-53-580-5048
}

Received: 4 February 2020; Accepted: 6 May 2020; Published: 13 May 2020

\begin{abstract}
This study aimed to determine how built environments affect pedestrian-vehicle collisions. The study examined pedestrian-vehicular crashes that occurred between 2013 and 2015 in Seoul, Korea, by comparing and analyzing different effects of the built environment on pedestrian-vehicle crashes. Specifically, the study analyzed built environment attributes, land use environment, housing types, road environment, and traffic characteristics to determine how these factors affect the severity of pedestrian injury. The results of the statistical analysis appear to infer that the built environment attributes had dissimilar impacts on pedestrian collisions, depending on the injury severity. In general, both incapacitating and non-incapacitating injuries appear to be more likely to be caused by the built environment than fatal and possible injuries. These results highlight the need to consider injury severity when implementing more effective interventions and strategies for ensuring pedestrian safety. However, because of the small sample size, an expanded research project regarding this issue should be considered, as it would contribute to the development and implementation of effective policies and interventions for pedestrian safety in Korea. This study therefore offers practical information regarding the development of such an expanded study to inform future traffic safety policies in Seoul to establish a "safe walking city."
\end{abstract}

Keywords: built environment; geographic information system; pedestrian safety; pedestrian-vehicle crash; severity of injury

\section{Introduction}

Background

Walking is the most fundamental mode of mobility. Being able to walk safely around a city is critical to creating and maintaining a comfortable, pleasant, and convenient city. There has been an increasing interest in walking because of its social, economic, health, and environmental benefits, as well as its application when constructing a sustainable transportation system. Walking is not only an important mode of transportation from a macro perspective, but it also benefits individuals' health at the micro level. Although the importance of walking has been emphasized previously in Korea, the number of vehicles and the length of road per capita have increased annually, and, with this, the number of collisions between pedestrians and vehicles. In 2015, among Organization for Economic Co-operation and Development (OECD) countries, Korea had one of the highest rates of traffic accidents, as shown in Table 1 [1]. Approximately 1.6 times as many people died in Korea per 100,000 people in traffic accidents than in any other OECD country. In addition, the number of traffic accidents per 100,000 people in Korea was approximately twice that of most OECD countries, with Korea seeing the third-highest number of traffic accidents per capita among all OECD countries. 
Table 1. Comparison of pedestrian-vehicle fatalities between Korea and OECD countries [1].

\begin{tabular}{cccc}
\hline Classification & Korea & $\begin{array}{c}\text { OECD } \\
\text { Average }\end{array}$ & $\begin{array}{c}\text { Korea's Ranking Among } \\
\text { 32 OECD Countries }\end{array}$ \\
\hline $\begin{array}{c}\text { Number of traffic accidents } \\
\text { per 100,000 people in 2015 } \\
\text { Number of fatalities }\end{array}$ & 458.4 & 222.3 & $31 / 32$ \\
per 100,000 people in 2015 & 9.1 & 5.6 & $31 / 35$ \\
\hline
\end{tabular}

The "Pedestrian Safety and Convenience Enhancement Act," which was enacted in Korea in 2012, aims to promote public welfare by creating a comfortable walking environment in which pedestrians can walk safely and conveniently, thus improving their quality of life [2]. In keeping with the national government's efforts, local governments have also focused more on building walkable environments that are safe from vehicle intrusion. Because it appears that the built environment plays a significant role in decreasing pedestrian-vehicle collisions [3], the efforts of urban planners and transportation engineers have been primarily on modifying the built environment to decrease the risk of pedestrian-vehicle collisions and to improve walkability [4]. Thus, to develop and implement more effective policy interventions for and investments in pedestrian safety, it is important to understand the link between the built environment and pedestrian collisions. Specifically, the extent to which the built environment affects pedestrian-vehicle collisions should be tested, based on the severity of pedestrian injuries.

\section{Literature Review}

\subsection{Pedestrian-Vehicle Collisions}

Pedestrian safety research has long been conducted in a number of fields, including transportation, public health, urban planning, and urban design. In addition to advancing efforts to promote walking [3,5-9], which has been highlighted in many studies, researchers should undertake a thorough examination of pedestrian safety from vehicles. In particular, studies should consider the importance of constructing built environments that ensure pedestrian safety via measures that prevent pedestrian-vehicle collisions. Studies have examined the effect of neighborhood built environments on pedestrian-vehicle collisions in different regions globally [3,5-11]. Park and Lee [12] analyzed the influence of the micro street environment on pedestrian accidents in Seoul, Korea, using street segment unit analysis. They found that vehicle traffic volume, pedestrian flow, commercial streets, and pedestrian crossings were closely related to pedestrian-vehicle collisions. Ukkusuri et al. [13] analyzed the role of built environments in the frequency of pedestrian collisions in New York City, USA, revealing that commercial areas, open spaces, and public transportation stops determined where people walked and, therefore, had an impact on traffic accidents. In addition, Park [14] analyzed the association between built environments and pedestrian-vehicle collisions at the census tract level in Seattle, USA, finding that turning intersections, traffic light density, mixed land use ratio, and number of bus stops significantly affected pedestrian safety. Lee and Lee [15] studied older people and children, who are classified as "transportation vulnerable," and found that the high densities of intersections and public transportation facilities were a threat to pedestrian safety.

Along with general studies on the association between pedestrian-vehicle collisions and built environments, many studies have analyzed pedestrian-vehicle collisions based on the severity of injuries. For example, Clifton et al. [4] performed a generalized ordered probit analysis in Baltimore, USA, to identify personal and environmental characteristics that were associated with the severity of injuries in pedestrian-vehicle collisions. This analysis revealed that children, male pedestrians, and older people were more likely to be injured fatally. Furthermore, Clifton et al. [4] and Tay et al. [7] found that pedestrian injuries were more severe when they occurred while crossing intersections. $\mathrm{Yu}$ [11] and Seo and Lee [16] conducted two studies, that analyzed pedestrian-vehicle collisions and 
injury severity by looking at census tract data and the micro-level within a $0.5 \mathrm{~km}$ radius, respectively. Both studies revealed that intersections, traffic control facilities, central bus lanes, and commercial areas were likely to be correlated with serious injury to pedestrians.

Recently, more systematic and contextual built environment data (such as on land use, road characteristics, and traffic attributes) have been examined for their effects on vehicle-pedestrian collisions [9,11,17]. Abdul-Aziz et al. [9] employed random parameter logit models to identify the determinants of pedestrian injury severity levels in five boroughs of New York City, USA. The study found significant associations between pedestrian-vehicle collisions and the number of lanes, road darkness, road surface, intersections, speed limit, vehicle type, presence of signal controls, parking facilities, and commercial and industrial land use, even though several significant variables showed different results for different boroughs. Yu [11] developed two multilevel models to identify factors related to the severity of pedestrian injury at two different scales. This study indicates that the density of intersections, the density of transit stops, the percentage of land use devoted to schools, and the percentage of land use devoted to parks, which were significant for the single-level model, failed to be significant for the multi-level model. These results also revealed that the risk of fatality and severe injury was less likely in areas with higher sidewalk density and greater percentages of commercial land use. This study demonstrated that intersection and traffic control devices were associated with a decrease in fatal and severe injuries, while increases in road darkness, speed limits, and population density led to a higher risk of fatality. Moudon et al. [18] studied the risk of pedestrian-vehicle collisions on state routes and city streets in King County, Washington, USA. Their study revealed an interesting association among home value, residential density, and injury severity, finding that lower neighborhood median home values and higher residential densities carried them a greater risk of fatal and severe injuries. The results of the study also indicated that areas with higher pedestrian activity did not guarantee pedestrian safety.

In addition to the studies mentioned above, many studies have attempted to identify various determinants affecting the severity of pedestrian injury. Among road environments and street characteristics, factors found to be relating to injury severity included crosswalks [19-25], intersections [26-30], number of lanes [21], sidewalks [31-33], traffic signals [29,34], street lights [5,22,35], road width [36], and road network [37]. For traffic-related environments, factors including traffic control devices [31,38], vehicle speed limits [17,20,28,38,39], auto types [17,28,36,40], and traffic volume [41,42] were found to have significant effects on pedestrian-vehicle collisions. With regard to land use characteristics, the relationship between land use and pedestrian fatalities was explored via educational facilities [43], commercial land use [38,44,45], residential land use [36,38], and mixed land uses [38]. In terms of individual factors relating to these collisions, several studies have considered gender [45], age $[28,36,46,47]$, and population density $[11,38]$ to be indicators of major crashes.

\subsection{Limitations of Prior Research and Differentiation of Research}

Based on the results of prior research, it appears that attributes of the built environment affect the incidence of pedestrian fatalities. Much of that research, however, has focused on analyzing how some part of the built environment affects pedestrian injuries, which fails to consider the overall systematic mechanism of the built environment; therefore, many walking-related studies miss some aspects of the built environment associated with pedestrian behavior. Pedestrian-vehicle collisions cannot be discussed separately from pedestrian walking behavior. It is better to include parameters related to pedestrian walking behavior. Therefore, this study tries to examine housing types [48,49], public transit [50,51], and road types [52,53]—how these factors relate to walking behavior could influence pedestrian fatalities. We extended the implications of the present study by including these potential factors to investigate the interaction between injury severity and the overall characteristics of the built environment, including land use, housing types, road environment, and traffic characteristics. 


\section{Methods}

\subsection{Data}

The present study was conducted using electronic crash data from pedestrian-vehicle collisions that occurred in Seoul, Korea, between 2013 and 2015. Over this three-year period, there were 33,106 accidents involving both pedestrians and vehicles. The electronic crash data were obtained at the borough level using the Traffic Accident Analysis System. At the time of the study, the population of Seoul was approximately 10 million, according to 2015 census data, and its land area was approximately $605 \mathrm{~km}^{2}$. The pedestrian-vehicle collisions examined in this study were classified into five categories - total pedestrian, fatal, incapacitating, non-incapacitating, and possible injuries-according to the severity of pedestrian injuries. To account for differences in the area for Seoul's 25 boroughs, the number of pedestrian injuries by level of severity was converted into a density ratio-number of pedestrian collisions per square kilometer for each borough.

Variables relating to the built environment that may influence pedestrian collisions were analyzed, such as land use, housing type, road environment, and traffic characteristics. Due to differences among the boroughs in terms of population and area, population density was employed as a controlling variable. To analyze the effect of neighborhood land use and housing type (data for which was obtained from the Korean Statistical Information System), this study examined the ratio of residential, commercial, and green areas, as well as high-rise multi-family and single-family housing, and housing in non-residential buildings. Road environment and traffic characteristics, data for which were provided by the Seoul Research Institute, were divided into two categories: public transportation and road/traffic facilities. The point-based data, including subway entrances and bus stops, were calculated by the area-based density of public transportation facilities. Roads were classified by hierarchy in the following order: main arterial, secondary arterial, collector, and local roads under transportation-related law in Korea. However, main arterial roads, which were defined as main roads that handle mass traffic volume and link major urban and rural areas, were not included in this study because pedestrians are less likely to encounter them. The variables related to pedestrian crossings were divided into three indicator categories: crosswalks with traffic signals; crosswalks without traffic signals; and number of crosswalks per road length. The first two were measured using the area-based density; the third using the length-based density. Through these different measures, accurate measurements of factors affecting pedestrian-vehicle crashes, even with the same variable, can be observed. Finally, the density of speed humps, which limit vehicle speed and could interfere with pedestrian walking [54], was observed in this study.

\subsection{Data Analysis}

Pedestrian-vehicle collisions possess a spatial attribute because they occur in space. Everything in space affects other things in space; however, things in close proximity have a greater effect on each other than things that are far apart. This concept is referred to as spatial autocorrelation, which is defined as a measure of spatial similarity between nearby observations [55]. If spatial autocorrelation is not considered in spatial analysis, the result of the spatial statistical analysis could be misinterpreted because of the violation of the statistical assumption that observations are independent from one another [56]. Verifying the spatial autocorrelation determines the validity of applying a spatial regression model. This study measured the spatial autocorrelation of pedestrian collision density, a dependent variable, through the value of Moran's index, using geographic information system (GIS) data. Moran's index has a value between -1 and +1 , which indicates the spatial similarity effect of the measured values [57]. A value closer to -1 indicates that dissimilar values cluster together, while a value closer to +1 indicates that similar values cluster together. If the value of Moran's index indicates the spatial autocorrelation of the spatial distribution of pedestrian-vehicle collisions, then spatial regression models should be used in the analysis; otherwise, the ordinary least squares (OLS) regression model should be employed [57]. 


\section{Results and Discussion}

\subsection{Spatial Distribution of Pedestrian-Vehicle Collisions}

Figure 1 illustrates the density of pedestrian-vehicle collisions in Seoul from 2013 to 2015 by severity type. Regardless of severity, the maps show that pedestrian collisions occurred frequently in the center of Seoul. In boroughs outside downtown Seoul, pedestrian-vehicle collisions appeared to be less clustered and more evenly dispersed throughout the city. However, a closer examination of the GIS maps showed that the spatial distribution varied according to severity type. For example, fatal injuries from pedestrian-vehicle collisions tended to occur more frequently in the southwestern area of Seoul, whereas possible injuries were more common in the southeastern area of Seoul. This distinction indicates that the frequency of collisions and severity of injuries varied according to regional characteristics. Ding et al. [58] suggested that local agencies need to develop geo-spatially discriminated policies to build safe walking environments. Therefore, it is necessary to look at the effects of the built environments, which may differ from borough to borough, on pedestrian-vehicle collisions according to severity type.

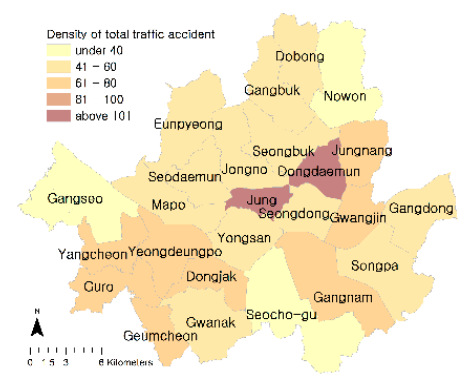

(a)

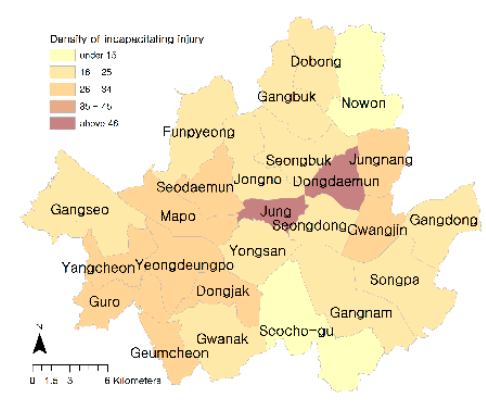

(c)

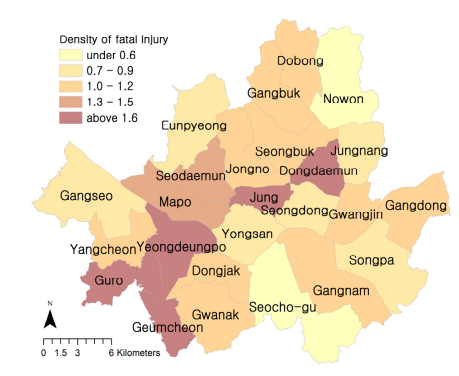

(b)

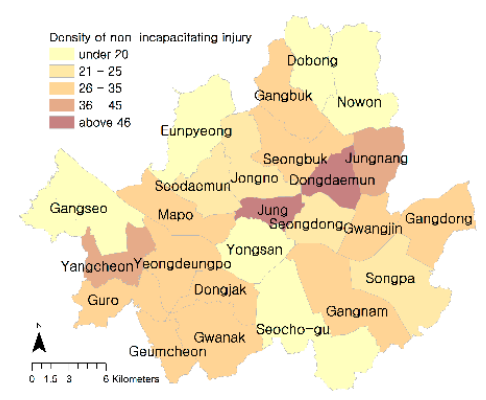

(d)

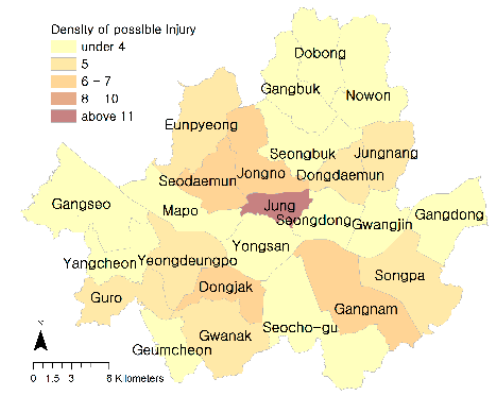

(e)

Figure 1. Spatial distribution of pedestrian injury severity: (a) Density of total pedestrian injuries; (b) Density of fatal injuries; (c) Density of incapacitating injuries; (d) Density of non-incapacitating injuries; and (e) Density of possible injuries. 


\subsection{Spatial Autocorrelation Analysis}

Table 2 shows the values of Moran's index results of spatial autocorrelation by severity type. Five models, including total pedestrian injuries, failed to have spatial dependence among the boroughs, meaning that pedestrian-vehicle collisions that occurred within each borough were less likely to be affected by an adjacent borough and more likely to be influenced by the nature of the borough. Therefore, this study employed an OLS-based regression model instead of spatial regression models.

Table 2. Spatial autocorrelation analysis.

\begin{tabular}{ccc}
\hline Severity & Moran's Index & $p$-Value \\
\hline Total pedestrian injury & -0.0157 & 0.8839 \\
Fatal injury & -0.2098 & 0.3590 \\
Incapacitating injury & 0.0810 & 0.4935 \\
Non-incapacitating injury & -0.0377 & 0.9825 \\
Possible injury & -0.0643 & 0.8823 \\
\hline
\end{tabular}

\subsection{Descriptive Statistics of the Variables}

Table 3 provides descriptive statistics of the variables considered in this study. All variables were tested with a Shapiro-Wilk test in SPSS to assess the assumption of normality. Normality analysis was conducted to determine whether the measured data met the assumption of parametric tests. Between 2013 and 2015, the average total density of pedestrian-vehicle collisions within the Seoul Metropolitan Government area was 59.39. When pedestrian-involved collisions occurred, incapacitating and non-incapacitating injuries were more common than fatal and possible injuries. As shown in the table, the boroughs had different population densities: the highest population density was 20 times that of the lowest population density. Residential areas accounted for the largest proportion of the area within boroughs, with some being more than $90 \%$. Regarding housing type, high-rise multi-family housing accounted for more than $50 \%$ of the houses in Seoul. The density of crosswalks without traffic signals was higher than the density of crosswalks with traffic signals.

Table 3. Descriptive statistics of variables.

\begin{tabular}{|c|c|c|c|c|c|c|}
\hline & Variables & Measurements & Mean & S.D. & Min & Max \\
\hline \multicolumn{7}{|c|}{ Dependent variable } \\
\hline \multicolumn{2}{|r|}{ Density of total pedestrian injuries } & $\# / \mathrm{km}^{2}$ & 59.39 & 19.99 & 32.32 & 113.25 \\
\hline \multicolumn{2}{|r|}{ Density of fatal injuries } & $\# / \mathrm{km}^{2}$ & 1.13 & 0.49 & 0.49 & 2.39 \\
\hline \multicolumn{2}{|r|}{ Density of incapacitating injuries } & $\# / \mathrm{km}^{2}$ & 25.66 & 8.89 & 13.74 & 50.00 \\
\hline \multicolumn{2}{|c|}{ Density of non-incapacitating injuries } & $\# / \mathrm{km}^{2}$ & 27.89 & 9.72 & 15.70 & 55.14 \\
\hline \multicolumn{2}{|r|}{ Density of possible injuries } & $\# / \mathrm{km}^{2}$ & 4.47 & 2.11 & 2.09 & 12.55 \\
\hline \multicolumn{7}{|c|}{ Independent variable } \\
\hline \multirow[t]{3}{*}{$\begin{array}{l}\text { Controlling } \\
\text { variable }\end{array}$} & Population density & $\# / \mathrm{km}^{2}$ & 19,437 & 13,040 & 3694 & 62,770 \\
\hline & Residential area ratio & $\%$ & 54.83 & 16.90 & 32.75 & 91.57 \\
\hline & Commercial area ratio & $\%$ & 5.05 & 7.35 & 1.14 & 36.27 \\
\hline \multirow{3}{*}{$\begin{array}{l}\text { Land use and } \\
\text { housing type }\end{array}$} & Green area ratio & $\%$ & 35.64 & 17.31 & 0.25 & 62.61 \\
\hline & Single-family housing ratio & $\%$ & 14.56 & 6.90 & 4.21 & 30.09 \\
\hline & High-rise multi-family housing ratio & $\%$ & 56.25 & 13.64 & 28.82 & 86.12 \\
\hline \multirow{10}{*}{$\begin{array}{l}\text { Road and traffic } \\
\text { characteristic }\end{array}$} & Housing in non-residential building ratio & $\%$ & 1.15 & 0.41 & 0.40 & 1.96 \\
\hline & Subway entrance density & $\# / \mathrm{km}^{2}$ & 2.46 & 2.03 & 0.72 & 11.24 \\
\hline & Bus stop density & $\# / \mathrm{km}^{2}$ & 14.65 & 4.48 & 7.55 & 27.95 \\
\hline & Secondary arterial road ratio & $\%$ & 4.04 & 2.80 & 0.00 & 12.26 \\
\hline & Collector road ratio & $\%$ & 1.70 & 1.65 & 0.00 & 6.25 \\
\hline & Local road ratio & $\%$ & 4.36 & 3.21 & 0.66 & 12.19 \\
\hline & Density of crosswalks with traffic signals & $\# / \mathrm{km}^{2}$ & 17.04 & 5.23 & 9.51 & 27.69 \\
\hline & Density of crosswalks without traffic signals & $\# / \mathrm{km}^{2}$ & 41.33 & 17.10 & 17.01 & 105.02 \\
\hline & Number of crosswalks per road length & $\# / \mathrm{km}$ & 4.22 & 1.71 & 2.47 & 11.32 \\
\hline & Speed hump density & $\# / \mathrm{km}^{2}$ & 16.56 & 7.77 & 4.96 & 35.45 \\
\hline
\end{tabular}




\subsection{Regression Analysis}

Table 4 shows the results of the general linear regression analysis for pedestrian collisions. Before undertaking the regression analysis in $\mathrm{R}$, the multicollinearity between the explanatory variables was examined. Because the collinear variables could have the same information regarding injury severity in this study, and could lead to inaccurate estimates of coefficient values, collinearity needed to be avoided [59]. Therefore, certain explanatory variables (such as commercial space ratio, green space ratio, single-family housing ratio, subway entrance density, and density of crosswalks without traffic signals), initially considered in this study, were excluded in the final analysis after preliminary testing.

The results of the analysis show that the explanatory power of the models for total pedestrian, incapacitation, and non-incapacitation injuries were higher than those for fatal and possible injuries. As Figure 1 shows, the analysis of total pedestrian injuries was similar to that for incapacitation and non-incapacitation injuries.

The effects of the indicators on pedestrian collisions were as follows: Population density, which was a proxy variable used to control exposure to pedestrian-vehicle collisions, was not statistically significant. The absence of an association between population density and pedestrian collisions in Seoul was not consistent with the significant influence found in prior research [11,38]. This finding indicates that pedestrian accidents in Seoul were more likely to be affected by environmental factors than by the number of pedestrians. It may also imply that the occurrence and severity of accidents was more likely to occur among vulnerable road users $[60,61]$. Therefore, in the future, it will be necessary for policies to take greater consideration of vulnerable road users, as well as improve the physical environment. However, this can also be seen as a limitation of the size of the spatial units, i.e., boroughs. The results may differ because of differences in the size of spatial units from other studies. Therefore, it is necessary to re-discuss the effects of population by analyzing them within a similar range of spatial units.

The proportion of residential areas shows a statistically positive relationship with total pedestrian, incapacitating, and non-incapacitating injuries. The results show that, the greater the number of residential areas, the more serious the injuries, coinciding with a previous study's [38] finding that fatal injuries tended to occur more in residential areas than in commercial areas. Accordingly, more deliberate attention should be paid to pedestrian safety in residential areas. High-rise multi-family housing, which accounted for the greatest percentage of residential areas in Seoul, failed to yield a statistically significant association with all types of injury severity. This result is within the same context as population density, with no statistical significance.

In addition, with respect to the proportion of housing in non-residential buildings (such as hotels, motels, or temporary dwellings), only total pedestrian and non-incapacitating injuries had a statistically significant influence. Therefore, the use of buildings may be more relevant to the likelihood of pedestrian injuries than their development density. This finding highlights that attention needs to be paid to neighborhood facilities at a micro-level, including parks, schools, children's playgrounds, restaurants, and convenience stores [62]. 
Table 4. Model estimation results for pedestrian injury severity.

\begin{tabular}{|c|c|c|c|c|c|c|c|c|c|c|c|c|c|c|c|c|c|}
\hline \multirow{2}{*}{ Classification } & \multirow{2}{*}{ Variables } & \multicolumn{4}{|c|}{ Total Pedestrian Injury } & \multicolumn{3}{|c|}{ Fatal Injury } & \multicolumn{3}{|c|}{ Incapacitating Injury } & \multicolumn{3}{|c|}{ Non-Incapacitating Injury } & \multicolumn{3}{|c|}{ Possible Injury } \\
\hline & & Coef. & S.E & $t$-Value & VIF & Coef. & S.E & $\mathrm{t}$-Value & Coef. & S.E & $\mathrm{t}$-Value & Coef. & S.E & $\mathrm{t}$-Value & Coef. & S.E & $\mathrm{t}$-Value \\
\hline & Constant & $-24.698 *$ & 10.606 & -2.329 & & 0.203 & 0.674 & 0.301 & -8.930 & 4.830 & -1.849 & $-0.000 *$ & 6.453 & -2.151 & 0.000 & 2.179 & -0.909 \\
\hline $\begin{array}{c}\text { Controlling } \\
\text { variable }\end{array}$ & Population density & 0.000 & 0.000 & -1.179 & 1.736 & -0.00 & 0.000 & -1.062 & -7.423 & 0.000 & -1.267 & -8.816 & 0.000 & -1.126 & 1.482 & 0.000 & 0.561 \\
\hline \multirow{2}{*}{$\begin{array}{l}\text { Land use and } \\
\text { housing type }\end{array}$} & Proportion of residential area & $0.410 * *$ & 0.107 & 3.825 & 2.018 & -0.001 & 0.007 & -0.160 & $0.169 * *$ & 0.049 & 3.474 & $0.228 * *$ & 0.065 & 3.507 & 0.011 & 0.022 & 0.497 \\
\hline & $\begin{array}{l}\text { Proportion of high-rise } \\
\text { multi-family housings }\end{array}$ & -0.087 & 0.131 & -0.665 & 1.973 & -0.004 & 0.008 & -0.538 & -0.057 & 0.060 & -0.947 & -0.016 & 0.080 & -0.198 & -0.010 & 0.027 & -0.380 \\
\hline \multirow{7}{*}{$\begin{array}{l}\text { Road and traffic } \\
\text { characteristic }\end{array}$} & $\begin{array}{l}\text { Proportion of housing in } \\
\text { non-residential buildings }\end{array}$ & $10.748^{*}$ & 4.34 & 2.476 & 1.98 & 0.010 & 0.276 & 0.037 & 3.676 & 1.977 & 1.860 & $5.261 *$ & 2.640 & 1.992 & 1.679 & 0.892 & 1.883 \\
\hline & Bus stop density & 0.724 & 0.404 & 1.794 & 2.017 & 0.021 & 0.026 & 0.816 & $0.400 *$ & 0.184 & 2.179 & 0.239 & 0.245 & 0.972 & 0.072 & 0.083 & 0.866 \\
\hline & Secondary arterial road ratio & $1.187 *$ & 0.523 & 2.272 & 1.316 & 0.052 & 0.033 & 1.557 & $0.513 *$ & 0.238 & 2.155 & $0.672 *$ & 0.318 & 2.115 & -0.048 & 0.107 & -0.447 \\
\hline & Collector road ratio & 0.422 & 1.268 & 0.333 & 2.686 & -0.009 & 0.081 & -0.111 & 0.748 & 0.578 & 1.296 & -0.761 & 0.772 & -0.987 & 0.462 & 0.261 & 1.772 \\
\hline & Local road ratio & 0.046 & 0.474 & 0.098 & 1.431 & -0.035 & 0.030 & -1.163 & -0.027 & 0.216 & -0.123 & 0.067 & 0.289 & 0.232 & 0.056 & 0.097 & 0.571 \\
\hline & $\begin{array}{l}\text { Density of crosswalks } \\
\text { with traffic signals }\end{array}$ & $1.878^{* *}$ & 0.342 & 5.496 & 1.969 & $0.058^{* *}$ & 0.022 & 2.688 & $0.874^{* *}$ & 0.156 & 5.616 & $0.997^{* *}$ & 0.208 & 4.797 & -0.077 & 0.070 & -1.101 \\
\hline & $\begin{array}{l}\text { Number of crosswalks } \\
\text { per road length }\end{array}$ & $3.827^{* *}$ & 1.047 & 3.656 & 1.978 & 0.013 & 0.066 & 0.197 & $1.178^{*}$ & 0.477 & 2.472 & $1.989 * *$ & 0.637 & 3.123 & $0.667^{* * *}$ & 0.215 & 3.102 \\
\hline \multirow{3}{*}{ Statistics } & $\begin{array}{l}\text { Speed hump density } \\
\mathrm{N}\end{array}$ & \multirow{2}{*}{\multicolumn{4}{|c|}{$\begin{array}{c}25 \\
0.947\end{array}$}} & 0.000 & $\begin{array}{l}0.013 \\
25\end{array}$ & -0.014 & $-0.197 *$ & $\begin{array}{l}0.095 \\
25\end{array}$ & -2.067 & $-0.289 *$ & $\begin{array}{l}0.127 \\
25\end{array}$ & -2.276 & 0.050 & $\begin{array}{l}0.043 \\
25\end{array}$ & 1.158 \\
\hline & R-Squared & & & & & \multicolumn{3}{|c|}{$\begin{array}{c}25 \\
0.642\end{array}$} & \multicolumn{3}{|c|}{0.945} & \multicolumn{3}{|c|}{0.917} & \multicolumn{3}{|c|}{0800} \\
\hline & Adjusted R-Squared & \multicolumn{4}{|c|}{0.903} & \multicolumn{3}{|c|}{0.340} & \multicolumn{3}{|c|}{0.898} & \multicolumn{3}{|c|}{0.848} & \multicolumn{3}{|c|}{0.630} \\
\hline \multicolumn{18}{|c|}{${ }^{*} p<0.05, * * p<0.01$} \\
\hline
\end{tabular}


Among the road and traffic characteristics, it was found that the density of bus stops, which may indicate characteristics leading to walking, failed to have an explanatory power of association with injury severity, except in the incapacitating injury model. This result may indicate that pedestrian-vehicle collisions occurring around bus stops may result in more incapacitating injuries than other injury types. Therefore, more specific effective pedestrian safety policies should be considered for edestrian safety around bus stops, which support walking and sustainable transport uses. Regarding road types, only the secondary arterial road ratio showed a statistically significant association with injury severity (excluding fatal and possible injuries), suggesting that people may be more seriously injured on high-traffic roads than on neighborhood-level roads. This finding implies that vehicle speed on the road (which was not considered in this study because of limitations in the data acquired) may be associated with the severity of pedestrian crashes. This result is consistent with the previous literature $[17,21,28,36]$. Therefore, policies and strategies are necessary for pedestrian safety on major roads where vehicle traffic is a priority.

The density of crosswalks with traffic signals was found to have statistical significance in all models, except for possible injury. In other words, pedestrian-vehicle collisions were more likely to result in serious injuries when such collisions occurred at crosswalks with traffic signals. This is likely to be caused by pedestrians crossing at a crosswalk when the pedestrian crossing light is red.

Therefore, pedestrians must be conscious of and comply with all signals to walk safely. In addition, from the driver's point of view, installation of the pedestrian detection system in cars is suggested to reduce the possibility of collisions. Oikawa et al. [63] asserted that the pedestrian detection system needs to be designed in manner to reduce the vehicle velocity at the moment of pedestrian contact. Interestingly, the number of crosswalks per road length was significantly correlated with injury severity, except for fatal injuries. Although these findings are consistent with prior research [20,21], Kim et al. [5] offered a contradictory finding, in that crossing at crosswalks was more likely to result in a lower risk of fatalities. This contradictory result may be confounded by other potentially influencing measures that were not considered in the study. However, the results of this study imply that pedestrian-vehicle crashes are likely to occur in neighborhoods with many crosswalks in general, beyond their relationship with the severity of accidents. Therefore, effective pedestrian safety programs, such as collision avoidance and pedestrian detection systems, are needed to reduce the likelihood of pedestrian crashes around crosswalks as well as the potential severity of pedestrian injuries. Xie et al. [27] demonstrated the importance of exclusive pedestrian signals for all crosswalks, which can contribute to reducing the risk of pedestrian-vehicle collisions.

Finally, it is surprising that, among the factors with statistical significance, the density of speed humps was the only measure to have a negative influence on injury severity. Speed humps were likely to play a significant role in decreasing the injury severity [64], even though the models of fatal and possible injuries did not yield statistically significant associations between pedestrian collisions and speed humps. As previously explained, in contrast to the tendency of secondary arterial road ratios to increase the likelihood of pedestrian crashes, collector and local roads did not show any association with the likelihood of crashes occurring. Therefore, policies that take advantage of the effectiveness of speed humps would be expected to play a role in reducing the possibility of pedestrian crashes on the collector and local roads.

\section{Conclusions}

This study examined how the severity of pedestrian injury related to aspects of built environments, such as land use, housing type, road type, and traffic characteristics. The research also examined how built environments influenced the risk of pedestrian-vehicle collisions according to the severity level of pedestrian injury. The findings of this study indicate that the measures' explanatory power depends on the severity of pedestrian injury. The density of crosswalks with traffic signals is only an indicator that can explain pedestrian crashes in the fatal injury model. The number of crosswalks is only an indicator that can explain pedestrian crashes in the possible injury model. It is also interesting to note 
that bus stop density plays a role in reducing pedestrian collisions in only the incapacitating injury model. Therefore, these interesting findings suggest that the built environmental characteristics of neighborhoods that affect pedestrian crashes vary according to the severity level of pedestrian injuries.

This study's findings offer several implications relating to pedestrian safety policy. First, special attention should be paid to residential areas over other land uses to ensure that people can walk safely in those areas. Second, special attention should be paid to the safety of pedestrians in areas where there are large proportions of arterial-level roads, which generally accommodate greater traffic flow than neighborhood-level streets. Third, the positive association of crosswalks with injury severity means that the crosswalks did not necessarily guarantee pedestrian safety, even if a road had more crosswalks installed or if traffic signals were equipped on the crosswalks. Therefore, this study suggests the need to highlight the importance of crosswalks for reducing the probability of pedestrian-vehicle collisions and for promoting pedestrian safety.

Even though this empirical study reveals a key finding — that the built environment has different impacts on pedestrian-vehicle collisions, depending on the severity of injury-this study has a few limitations, which should be developed further through future research and investigation. One limitation was the small sample size, with only 25 observations. Pedestrian collision data were aggregated to the borough level only, because the Korea Road Traffic Authority does not provide more detailed location information for pedestrian-vehicle collisions. Therefore, further micro-level research using data that include the location information of pedestrian-vehicle accidents will be needed in the future, to provide more precise information about the influence of the built environment on pedestrian-involved collisions in Korea. In particular, spatial analysis at the micro level may reveal spatial autocorrelation of pedestrian-vehicle collisions. By controlling spatial autocorrelation at the micro level, the impact of the built environment on pedestrian injury severity can be grasped more accurately. A second limitation is that specific demographic information for both the injured pedestrians and the drivers was not included; this should be included in future research to enhance the model's ability to identify factors influencing collisions. In particular, having possible and fatal injuries in the same metric will be problematic, because this does not reflect the societal cost of these crashes; additionally, it could result in estimates being biased and inconsistent. Traffic volume and pedestrian volume could be contributing factors that directly and/or indirectly affect pedestrian injury severity. However, this study fails to consider these two potential indicators and instead considers population density because of the limited availability of data. It is expected that in future a more detailed study could be conducted at the micro-level if relevant data is available. In addition, the location data of collisions as well as the personal information of those involved, which are not available because of the lack of data in Korea, should be organized and managed by building a robust data platform.

This study indicates that, by carefully establishing a built environment in which pedestrians and vehicles interact safely, a city or country could decrease pedestrian risk exposure. The potential severity of pedestrian injuries has long been a major concern for those involved in transportation, public health, and urban planning. This study suggests that more deliberate research regarding this issue could contribute to the development and implementation of effective policies and interventions for pedestrian safety in Korea.

Author Contributions: S.-H.P.; conceived and designed the research and wrote the paper; M.-K.B.; analyzed the data. All authors have read and agreed to the published version of the manuscript.

Funding: This work was supported by the National Research Foundation of Korea (NRF) (No. NRF-2018R1D1A1B07050844).

Acknowledgments: This work was supported by the National Research Foundation of Korea (NRF) grant funded by the Korean Government (MEST) (No. NRF-2018R1D1A1B07050844). This research was based on the data provided in the "2016 Seoul Research Papers Competition" organized by the Seoul Research Institute. This research was developed and revised based on the preliminary study presented at the "2017 International Conference on East Asian Architecture and City" (2017 icEAAC).

Conflicts of Interest: The authors declare no conflicts of interest. 


\section{References}

1. Organisation for Economic Co-operation and Development(OECD). Available online: http://taas.koroad.or.kr/

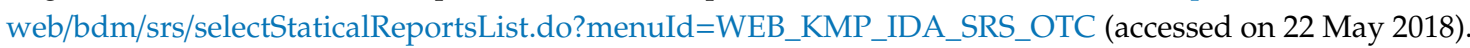

2. Korea Legislation Research Institute (KLRI). Available online: https://elaw.klri.re.kr/kor_service/lawView.do? hseq $=45750 \&$ lang=ENG (accessed on 19 April 2018).

3. Retting, R.A.; Ferguson, S.A.; McCartt, A.T. A Review of Evidence-Based Traffic Engineering Measures Designed to Reduce Pedestrian-Motor Vehicle Crashes. Am. J. Public Health 2003, 93, 1456-1463. [CrossRef]

4. Clifton, K.; Burnier, C.V.; Akar, G. Severity of injury resulting from pedestrian-vehicle crashes: What can we learn from examining the built environment? Transp. Res. Part D Transp. Environ. 2009, 14, 425-436. [CrossRef]

5. Kim, J.-K.; Ulfarsson, G.F.; Shankar, V.; Kim, S. Age and pedestrian injury severity in motor-vehicle crashes: A heteroskedastic logit analysis. Accid. Anal. Prev. 2008, 40, 1695-1702. [CrossRef] [PubMed]

6. Narayanamoorthy, S.; Paleti, R.; Bhat, C.R. On accommodating spatial dependence in bicycle and pedestrian injury counts by severity level. Transp. Res. Part B Methodol. 2013, 55, 245-264. [CrossRef]

7. Tay, R.; Choi, J.; Kattan, L.; Khan, A. A Multinomial Logit Model of Pedestrian-Vehicle Crash Severity. Int. J. Sustain. Transp. 2011, 5, 233-249. [CrossRef]

8. Wier, M.; Weintraub, J.; Humphreys, E.H.; Seto, E.; Bhatia, R. An area-level model of vehicle-pedestrian injury collisions with implications for land use and transportation planning. Accid. Anal. Prev. 2009, 41, 137-145. [CrossRef] [PubMed]

9. Aziz, H.A.; Ukkusuri, S.; Hasan, S. Exploring the determinants of pedestrian-vehicle crash severity in New York City. Accid. Anal. Prev. 2013, 50, 1298-1309. [CrossRef]

10. Koopmans, J.M.; Friedman, L.; Kwon, S.; Sheehan, K.M. Urban crash-related child pedestrian injury incidence and characteristics associated with injury severity. Accid. Anal. Prev. 2015, 77, 127-136. [CrossRef]

11. Yu, C.-Y. Built Environmental Designs in Promoting Pedestrian Safety. Sustaiability 2015, 7, 9444-9460. [CrossRef]

12. Park, C.Y.; Lee, S.G. An analysis of the characteristics of street environment affecting pedestrian-Applications of street segment analysis unit and spatial statistics. J. Urban Des. Inst. Korea 2016, 17, 105-121. (In Korean)

13. Ukkusuri, S.; Miranda-Moreno, L.F.; Ramadurai, G.; Isa-Tavarez, J. The role of built environment on pedestrian crash frequency. Saf. Sci. 2012, 50, 1141-1151. [CrossRef]

14. Park, S.-H. The Effect of the Neighborhood Built Environment on Pedestrian-Vehicle Collisions - Focused on the Cases of the City of Seattle, Washington, US. J. Korea Plan. Assoc. 2014, 49, 143. [CrossRef]

15. Lee, S.Y.; Lee, J.S. Neighborhood environmental factors affecting child and old adult pedestrian accident. J. Urban Des. Inst. Korea 2014, 15, 5-15. (In Korean)

16. Seo, J.; Lee, S. A Study on the Physical Environmental Factors Influencing Pedestrian Traffic Accidents in Seoul, Korea: Focused on the 2014 TAAS Data. J. Korea Plan. Assoc. 2016, 51, 197. [CrossRef]

17. Kim, J.-K.; Ulfarsson, G.F.; Shankar, V.; Mannering, F. A note on modeling pedestrian-injury severity in motor-vehicle crashes with the mixed logit model. Accid. Anal. Prev. 2010, 42, 1751-1758. [CrossRef]

18. Moudon, A.V.; Lin, L.; Jiao, J.; Hurvitz, P.; Reeves, P. The risk of pedestrian injury and fatality in collisions with motor vehicles, a social ecological study of state routes and city streets in King County, Washington. Accid. Anal. Prev. 2011, 43, 11-24. [CrossRef]

19. Zegeer, C.V.; Stutts, J.C.; Huang, H.F.; Zhou, M.; Rodgman, E.A. analysis of elderly pedestrian accidents and recommended countermeasures. J. Saf. Res. 1996, 27, 128. [CrossRef]

20. Leden, L.; Garder, P.; Johansson, C. Safe pedestrian crossings for children and elderly. Accid. Anal. Prev. 2006, 38, 289-294. [CrossRef] [PubMed]

21. Sze, N.N.; Wong, S.C. Diagnostic analysis of the logistic model for pedestrian injury severity in traffic crashes. Accid. Anal. Prev. 2007, 39, 1267-1278. [CrossRef]

22. Siddiqui, N.A.; Chu, X.; Guttenplan, M. Crossing Locations, Light Conditions, and Pedestrian Injury Severity. Transp. Res. Rec. J. Transp. Res. Board 2006, 1982, 141-149. [CrossRef]

23. Koepsell, T.D.; McCloskey, L.; Wolf, M.; Moudon, A.V.; Buchner, D.; Kraus, J.; Patterson, M. Crosswalk markings and the risk of pedestrian-motor vehicle collisions in older pedestrians. JAMA 2002, 288, 2136-2143. [CrossRef] [PubMed] 
24. Feliciani, C.; Crociani, L.; Gorrini, A.; Vizzari, G.; Bandini, S.; Nishinari, K. A simulation model for non-signalized pedestrian crosswalks based on evidence from on field observation. Intell. Artif. 2017, 11, 117-138. [CrossRef]

25. Feliciani, C.; Gorrini, A.; Crociani, L.; Vizzari, G.; Nishinari, K.; Bandini, S. Calibration and validation of a simulation model for predicting pedestrian fatalities at unsignalized crosswalks by means of statistical traffic data. J. Traffic Transp. Eng. (Engl. Ed.) 2020, 7, 1-18. [CrossRef]

26. Gorrini, A.; Crociani, L.; Vizzari, G.; Bandini, S. Observation results on pedestrian-vehicle interactions at non-signalized intersections towards simulation. Transp. Res. Part F Traffic Psychol. Behav. 2018, 59, $269-285$. [CrossRef]

27. Xie, S.Q.; Dong, N.; Wong, S.; Huang, H.; Xu, P. Bayesian approach to model pedestrian crashes at signalized intersections with measurement errors in exposure. Accid. Anal. Prev. 2018, 121, 285-294. [CrossRef]

28. Lee, C.; Abdel-Aty, M. Comprehensive analysis of vehicle-pedestrian crashes at intersections in Florida. Accid. Anal. Prev. 2005, 37, 775-786. [CrossRef]

29. Haleem, K.; Alluri, P.; Gan, A. Analyzing pedestrian crash injury severity at signalized and non-signalized locations. Accid. Anal. Prev. 2015, 81, 14-23. [CrossRef]

30. Murphy, B.; Levinson, D.; Owen, A. Evaluating the Safety in Numbers effect for pedestrians at urban intersections. Accid. Anal. Prev. 2017, 106, 181-190. [CrossRef]

31. Ossenbruggen, P.J.; Pendharkar, J.; Ivan, J. Roadway safety in rural and small urbanized areas. Accid. Anal. Prev. 2001, 33, 485-498. [CrossRef]

32. McMahon, P.; Duncan, C.; Stewart, J.; Zegeer, C.; Khattak, A.J. Analysis of Factors Contributing to "Walking Along Roadway" Crashes. Transp. Res. Rec. J. Transp. Res. Board 1999, 1674, 41-48. [CrossRef]

33. Osama, A.; Sayed, T. Evaluating the impact of connectivity, continuity, and topography of sidewalk network on pedestrian safety. Accid. Anal. Prev. 2017, 107, 117-125. [CrossRef] [PubMed]

34. Shankar, V.; Ulfarsson, G.F.; Pendyala, R.M.; Nebergall, M.B. Modeling crashes involving pedestrians and motorized traffic. Saf. Sci. 2003, 41, 627-640. [CrossRef]

35. Amoh-Gyimah, R.; Aidoo, E.N.; Akaateba, M.A.; Appiah, S.K. The effect of natural and built environmental characteristics on pedestrian-vehicle crash severity in Ghana. Int. J. Inj. Control. Saf. Promot. 2016, 24, 459-468. [CrossRef] [PubMed]

36. Zajac, S.S.; Ivan, J. Factors influencing injury severity of motor vehicle-crossing pedestrian crashes in rural Connecticut. Accid. Anal. Prev. 2003, 35, 369-379. [CrossRef]

37. Guo, Q.; Xu, P.; Pei, X.; Wong, S.; Yao, D. The effect of road network patterns on pedestrian safety: A zone-based Bayesian spatial modeling approach. Accid. Anal. Prev. 2017, 99, 114-124. [CrossRef]

38. Graham, D.J.; Glaister, S. Spatial Variation in Road Pedestrian Casualties: The Role of Urban Scale, Density and Land-use Mix. Urban Stud. 2003, 40, 1591-1607. [CrossRef]

39. Li, D.; Ranjitkar, P.; Zhao, Y.; Yi, H.; Rashidi, S. Analyzing pedestrian crash injury severity under different weather conditions. Traffic Inj. Prev. 2016, 18, 1-4. [CrossRef]

40. Lefler, D.E.; Gabler, H. The fatality and injury risk of light truck impacts with pedestrians in the United States. Accid. Anal. Prev. 2004, 36, 295-304. [CrossRef]

41. Davis, G.A. Relating Severity of Pedestrian Injury to Impact Speed in Vehicle-Pedestrian Crashes: Simple Threshold Model. Transp. Res. Rec. J. Transp. Res. Board 2001, 1773, 108-113. [CrossRef]

42. Jang, K.; Park, S.H.; Kang, S.; Song, K.H.; Kang, S.; Chung, S. Evaluation of Pedestrian Safety. Transp. Res. Rec. J. Transp. Res. Board 2013, 2393, 104-116. [CrossRef]

43. Clifton, K.; Kreamer-Fults, K. An examination of the environmental attributes associated with pedestrian-vehicular crashes near public schools. Accid. Anal. Prev. 2007, 39, 708-715. [CrossRef] [PubMed]

44. Loukaitou-Sideris, A.; Liggett, R.; Sung, H.-G. Death on the Crosswalk. J. Plan. Educ. Res. 2007, 26, 338-351. [CrossRef]

45. Clifton, K.J.; Burnier, C.V.; Kreamer-Fults, K. Women's involvement in pedestrian-vehicle crashes: Influence of personal and environmental factors. In Proceedings of the Research on Women's Issues in Transportation: Report of a Conference, Chicago, IL, USA, 18-20 November 2004; Volume 35, pp. 155-162, ISBN 0309093945.

46. Al-Ghamdi, A.S. Pedestrian-vehicle crashes and analytical techniques for stratified contingency tables. Accid. Anal. Prev. 2002, 34, 205-214. [CrossRef] 
47. Oxley, J.; Ihsen, E.; Fildes, B.N.; Charlton, J.L.; Day, R.H. Crossing roads safely: An experimental study of age differences in gap selection by pedestrians. Accid. Anal. Prev. 2005, 37, 962-971. [CrossRef] [PubMed]

48. Lail, P.; McCormack, G.R.; Rock, M.J. Does dog-ownership influence seasonal patterns of neighbourhood-based walking among adults? A longitudinal study. BMC Public Health 2011, 11, 148. [CrossRef] [PubMed]

49. Crane, R.; Crepeau, R. Does neighborhood design influence travel? A behavioral analysis of travel diary and GIS data. Transp. Res. Part D Transp. Environ. 1998, 3, 225-238. [CrossRef]

50. Mavoa, S.; Witten, K.; McCreanor, T.; O'Sullivan, D. GIS based destination accessibility via public transit and walking in Auckland, New Zealand. J. Transp. Geogr. 2012, 20, 15-22. [CrossRef]

51. Lachapelle, U.; Noland, R.B. Does the commute mode affect the frequency of walking behavior? The public transit link. Transp. Policy 2012, 21, 26-36. [CrossRef]

52. Cerin, E.; Lee, K.-Y.; Barnett, A.; Sit, C.H.; Cheung, M.-C.; Chan, W.-M. Objectively-measured neighborhood environments and leisure-time physical activity in Chinese urban elders. Prev. Med. 2013, 56, 86-89. [CrossRef]

53. Hou, N.; Popkin, B.M.; Jacobs, D.R., Jr.; Song, Y.; Guilkey, D.; Lewis, C.E.; Gordon-Larsen, P. Longitudinal associations between neighborhood-level street network with walking, bicycling, and jogging: The CARDIA study. Health Place 2010, 16, 1206-1215. [CrossRef]

54. Tester, J.M.; Rutherford, G.W.; Wald, Z.; Rutherford, M.W. A Matched Case-Control Study Evaluating the Effectiveness of Speed Humps in Reducing Child Pedestrian Injuries. Am. J. Public Health 2004, 94, 646-650. [CrossRef] [PubMed]

55. Cliff, A.D.; Ord, J.K. Spatial Autocorrelation (Monographs in Spatial Environmental Systems Analysis), 1st ed.; Pion Limited: London, UK, 1973; ISBN 9780850860368.

56. Anselin, L. Spatial Econometrics: Methods and Models; Springer Science and Business Media LLC: Berlin, Germany, 1988; Volume 4, ISBN 9789048183111.

57. Dormann, C.F.; McPherson, J.; Araujo, M.B.; Bivand, R.; Bolliger, J.; Carl, G.; Davies, R.G.; Hirzel, A.; Jetz, W.; Kissling, W.D.; et al. Methods to account for spatial autocorrelation in the analysis of species distributional data: A review. Ecography 2007, 30, 609-628. [CrossRef]

58. Ding, C.; Chen, P.; Jiao, J. Non-linear effects of the built environment on automobile-involved pedestrian crash frequency: A machine learning approach. Accid. Anal. Prev. 2018, 112, 116-126. [CrossRef] [PubMed]

59. Mason, C.H.; Perreault, W.D. Collinearity, Power, and Interpretation of Multiple Regression Analysis. J. Mark. Res. 1991, 28, 268. [CrossRef]

60. Cai, Q.; Abdel-Aty, M.; Lee, J. Macro-level vulnerable road users crash analysis: A Bayesian joint modeling approach of frequency and proportion. Accid. Anal. Prev. 2017, 107, 11-19. [CrossRef]

61. Tasic, I.; Elvik, R.; Brewer, S. Exploring the safety in numbers effect for vulnerable road users on a macroscopic scale. Accid. Anal. Prev. 2017, 109, 36-46. [CrossRef]

62. Lee, J.; Abdel-Aty, M.; Choi, K.; Huang, H. Multi-level hot zone identification for pedestrian safety. Accid. Anal. Prev. 2015, 76, 64-73. [CrossRef]

63. Oikawa, S.; Matsui, Y.; Doi, T.; Sakurai, T. Relation between vehicle travel velocity and pedestrian injury risk in different age groups for the design of a pedestrian detection system. Saf. Sci. 2016, 82, 361-367. [CrossRef]

64. Arbogast, H.; Patao, M.; Demeter, N.; Bachman, S.L.; Devietti, E.; Upperman, J.S.; Burke, R.V. The effectiveness of installing a speed hump in reducing motor vehicle accidents involving pedestrians under the age of 21. J. Transp. Health 2018, 8, 30-34. [CrossRef]

(C) 2020 by the authors. Licensee MDPI, Basel, Switzerland. This article is an open access article distributed under the terms and conditions of the Creative Commons Attribution (CC BY) license (http://creativecommons.org/licenses/by/4.0/). 